\title{
Ultrasound Guided Hydrostatic Reduction of Intussusception Using Saline Enema in Pediatric Population, Does It Worth?
}

\begin{abstract}
a Department of Radiology, Benha faculty of medicine, Banha University, Egypt. b Department of Radiology, Benha Children Hospital, Benha, Egypt.
\end{abstract}

Medhat M. Refaat ${ }^{\text {a }}$, Shorouk Z. Abdel Aziz ${ }^{\text {a }}$, Hadeel B. Abdelmageed ${ }^{\mathrm{b}}$
Correspondence to: Hadeel B. Abdelmageed, Department of Radiology, Benha Children Hospital, Benha, Egypt.

Email:

doidobadr@gmail.com

Received: 30 May 2021

Accepted: 4 December 2021

\begin{abstract}
:
Background: Intussusception is an occlusive-strangulation form of intestinal obstruction, and all required precautions should be adopted as soon as possible to guarantee quick diagnosis and treatment in order to avoid intestinal ischaemia and necrosis. When facilities are available, nonoperative reduction is the first line of treatment; if that fails, operative management is the next logical step. Aim of work: The purpose of this study is to see how successful and safe it is to reduce intussusception with normal saline enema under guidance of ultrasound. Patients and methods: Our study comprised 37 children and was carried out at Benha Children's Hospital. Their ages varied from 4 to 36 months, with an 8-month median. Intussusceptions were diagnosed in all of them. Under ultrasound guidance, we used a sustained pressure of $100-120 \mathrm{~cm} \mathrm{H} 2 \mathrm{O}$ of saline enema per rectum and waited until the intussusceptum decreased or the retrograde
\end{abstract} movement ceased for up to 15 minutes. Results: The successful reduction rate was $89.2 \%$. However, the recurrence rate was $18.7 \%$, with successful non-operative reduction of all recurred cases. Only two of them required additional scheduled surgery due to pathological lead points. In the series, no procedure-related problems occurred. There were also no deaths. Conclusion: Because USGHR is a safe, effective procedure with a high success rate that does not require radiation exposure, we advocate it as the standard procedure and a suitable alternative to surgical surgery for managing paediatric intussusception.

Keywords: Hydrostatic reduction; Pediatric intussusception; Saline; Ultrasound-guided. 


\section{Introduction:}

Intussusception occurs when an intestinal segment telescopes or folds back on itself, blocking food and fluid passage, resulting in vein congestion and intestinal wall edema (1).

In pediatrics, the majority of intussusceptions (90\%) are ileocolic with the reminder $(10 \%)$ being ileoileal or colocolic (2).

Small intestinal blockages in infants and toddlers are most commonly caused by idiopathic intussusception. The global average yearly incidence is at 5-250 per 100,000 live births (3).

It is most common between the ages of 6 and 36 months. Approximately $60 \%$ of children with intussusception are under the age of one year, and 80-90 percent are under the age of two years (4).

Outside of this peak age group, the existence of pathologic lead points such as enlarged lymph nodes, ileo-ileal intussusceptions, Meckel's diverticulum, inflamed Peyer's patches and colonic polyps should always be suspected (5). In the paediatric population, non-operative reduction of the intussusceptum using air or liquid enemas is usually the first step in diagnosis and treatment (6).

Most children in high-income countries are diagnosed immediately using ultrasonography or radiography, and the bowel will return to normal following a nonsurgical procedure of injecting a liquid or gas into the rectum (enema). Surgery is often highly successful in more serious cases. In low-income nations, however, many children will die before seeking care; for those who do, surgery is frequently the primary form of diagnosis and treatment, with around $10 \%$ mortality rate (7).

The non-surgical hydrostatic reduction of an intussusception with barium enema or pneumatic reduction under fluoroscope guidance is associated with significant radiation exposure and the likelihood of intestinal perforation. However, the hydrostatic reduction of an intussusception under ultrasound guidance is a highly safe approach since the whole approach is observed by real-time ultrasound. Furthermore, being a non-invasive process with a high success rate, this therapy has emerged as an effective alternative to surgery (5). 
Since ultrasound is frequently the first imaging modality used to diagnose intussusception (8), hydrostatic reduction can be done promptly in the ultrasound room once the diagnosis has been made (9).

In our study, we used saline enema to reduce intussusception masses, under ultrasound guidance to show its efficacy and safety in pediatrics in our institution.

\section{Patients and methods:}

\section{Design and population:}

This cross-sectional study was conducted on paediatric intussusception patients who were expected to benefit from the USGHR (Ultrasound-Guided Hydrostatic Reduction). From July 2020 to January 2021, it was carried out at Benha Children's Hospital (6 months duration). Intussusception was detected in a total of 40 children, with ultrasound confirmation. In 37 of the patients, USGHR was attempted after exclusion criteria were met. There were 19 males and 18 girls, ranging in age from 4 to 36 months, with an average age of 8 months.

\section{Ethics and inclusion/exclusion criteria:}

The Ethics and Research Committee of Benha Children's Hospital (BENCH) and the Benha Faculty of Medicine gave their approval to the study. Patients who presented to our hospital's emergency department were enrolled in the study. The process was explained to all parents or guardians of patients with suspected intussusception, and they signed written informed consent to participate in the study.

\section{The following are the inclusion criteria} for the population of patients who have chosen to undergo USGHR:

- A child is proven to have intussusception by ultrasound.

- All children with a history of red currant jelly stool and a palpable abdominal lump were referred to the radiology department.

- Cases of a specific pediatric age group (up to 36 months).

- Patients with no contraindications for the procedure which includes peritonitis, perforation evidence, and non-responsive shock which necessitates surgery (10).

The exclusion criteria included the following:

- Patients are not confirmed to have intussusception by ultrasound.

- Any contraindication of conventional reduction which includes peritonitis, 
intestinal perforation, and nonresponsive shock that necessitates surgery.

- Patients who required urgent surgery owing to acute abdominal disease.

- Patients with spontaneous reduction.

- Adult \& elderly patients.

- Patients refused to do the procedure.

\section{Outcome measures and measurement:}

Successful reduction, unsuccessful reduction with further surgical intervention, perforation during reduction, and recurrence of intussusception following therapy were the outcomes.

A successful reduction was defined as the full disappearance of the intussusceptum with saline reflux into the ileum.

A failed reduction was described as one in which the intussusceptum could not be totally reduced or the gut had been perforated.

\section{Procedure in details:}

All patients were handled with nil per os (NOS), suitable cannula and Ryle insertion for proper hydration and electrolyte correction, and urinary catheter insertion to prepare the patient for laparotomy if reduction was unsuccessful.

To confirm the diagnosis of intussusception, a radiologist used General Electric company (GE) health care model GE Logic P6 ultrasound equipment with a 10-12 $\mathrm{MHz}$ high frequency linear probe to do an ultrasound scan of the abdomen in the radiology ultrasound room.

An attending radiologist and paediatric surgeon performed USGHR after confirmation. Prior to the treatment, an oncall anesthesiologist and peri-operative nurses were alerted in case of complications such as perforation or failed reduction that required surgery.

With the patient lying supine, a suitable Foley catheter $(10 \mathrm{~F}-18 \mathrm{~F})$ was placed into the rectum and then the balloon was inflated. Only in the most extreme circumstances, little sedation was given. Normal saline, prewarmed to body temperature was placed at $120 \mathrm{~cm}$ above the table level as described before (11), and allowed to flow into the colon under gravity. During reduction, saline flow and the regression of the intussusceptum were observed by ultrasonography. The peritoneal cavity was checked for abrupt fluid increases and 
simultaneous fluid loss from the colon, suggestive of bowel perforation.

A maximum of three reductions were permitted, each lasting 5 to 15 minutes with a half-hour to two-hour break if practicable. If the patients did not reduce after the third try, the procedures were promptly terminated and they were transferred to the operating room for surgical reduction or resection with bowel anastomosis.

All patients who had a successful USGHR procedure were monitored in the ward for at least 24 hours to assess any complications and recurrence.

\section{Statistical methods:}

SPSS vs.25 was used for data processing and statistical analysis (IBM, Armonk, New York, United States).

\section{CASES:}

Case 1: A baby girl, 8 months old, presented with abdominal colics, vomiting and irritability for 36 hours ago. An Ultrasound scan revealed evidence of ileocolic intussusception mass. (a) transverse plane showing a heterogeneous target like mass with multiple concentric rings (arrow). (b) a pseudokidney shaped mass (arrow). The case had a successful Hydrostatic reduction under the guidance of ultrasound. (c) The typical sandwich sign (arrow) is seen as the head of intussusception is forced backwards towards the ileocecal valve by fluid enema. (d) In the longitudinal plane, the head of intussusception (arrow) is surrounded by echo free fluid proximal to the ileocecal valve. (e) The ileocecal valve (arrows) is visible after effective reduction, with fluid flowing freely into the ileum. (f) The reduction enema fluid is visualized being poured into the ileal loops (honey comb appearance) (Figure 1).

Case 2: A 31-month-old baby girl presented with recent rectal prolapse with red currant jelly stool for the last 24 hours. An ultrasonographic scan showed an idiopathic ileocolic intussusception. (a) Sandwich or pseudokidney sign. (b) Presence of free fluid and distended proximal bowel loop. The rectal prolapse was manually reduced by the pediatric surgeon, then the mass was reduced by hydrostatic reduction successfully (Figure 2).

Case 3: A six-month old girl presented with recent rectal bleeding with a history of vomiting and diarrhea one day before. An idiopathic intussusception mass was discovered via ultrasound. (a) a 
heterogeneous mass with central multiple concentric rings (target sign) (b) US scan after hydrostatic reduction showed the presence of a residual mass. The baby was sent to the surgery room for manual reduction (Figure 3).

Case 4: Ileocolic intussusception mass in a patient of Henoch-Schönlein purpura presented with multiple joint pain, purpuric rash and abdominal pain. (a) Initial ultrasound scanning showed the target sign of intussusception. (b) The mass with severe bowel wall thickening (arrow). (c) On the follow-up scan after reduction, a transverse image shows numerous enlarged mesenteric lymph nodes (arrows). (d) A sagittal image shows marked thickening of the bowel wall (arrows) (Figure 4).

Case 5: A 35-month- old baby presented with chronic abdominal pain increasing with eating, became more intense 12 hours ago.
Ultrasound revealed: (a) The intussusception as a target sign in the short axis. (b) a typical sonographic appearance of a polyp containing small cysts with the evidence of its stalk. (c \& d) During saline infusion per rectum, ultrasound images show the polyp (arrows) surrounded by fluid, confirming its colonic intraluminal location. The case recurred at the morning. It was juvenile polyposis (Figure 5).

Case 6: A boy, 30 months old presented with abdominal pain and recent rectal bleeding. Initial ultrasound scanning revealed: (a) a large heterogeneous mass (arrows) with a central target like structure. (b) Sagittal image showing telescoped two bowels (between open arrows) and a hypoechoic mass at the neck of the intussusception (arrowheads), K (kidney). It failed with hydrostatic reduction and was sent to the surgical theatre for manual reduction, where it was found to have pathologically proven Burkitt's lymphoma mass (Figure 6). 


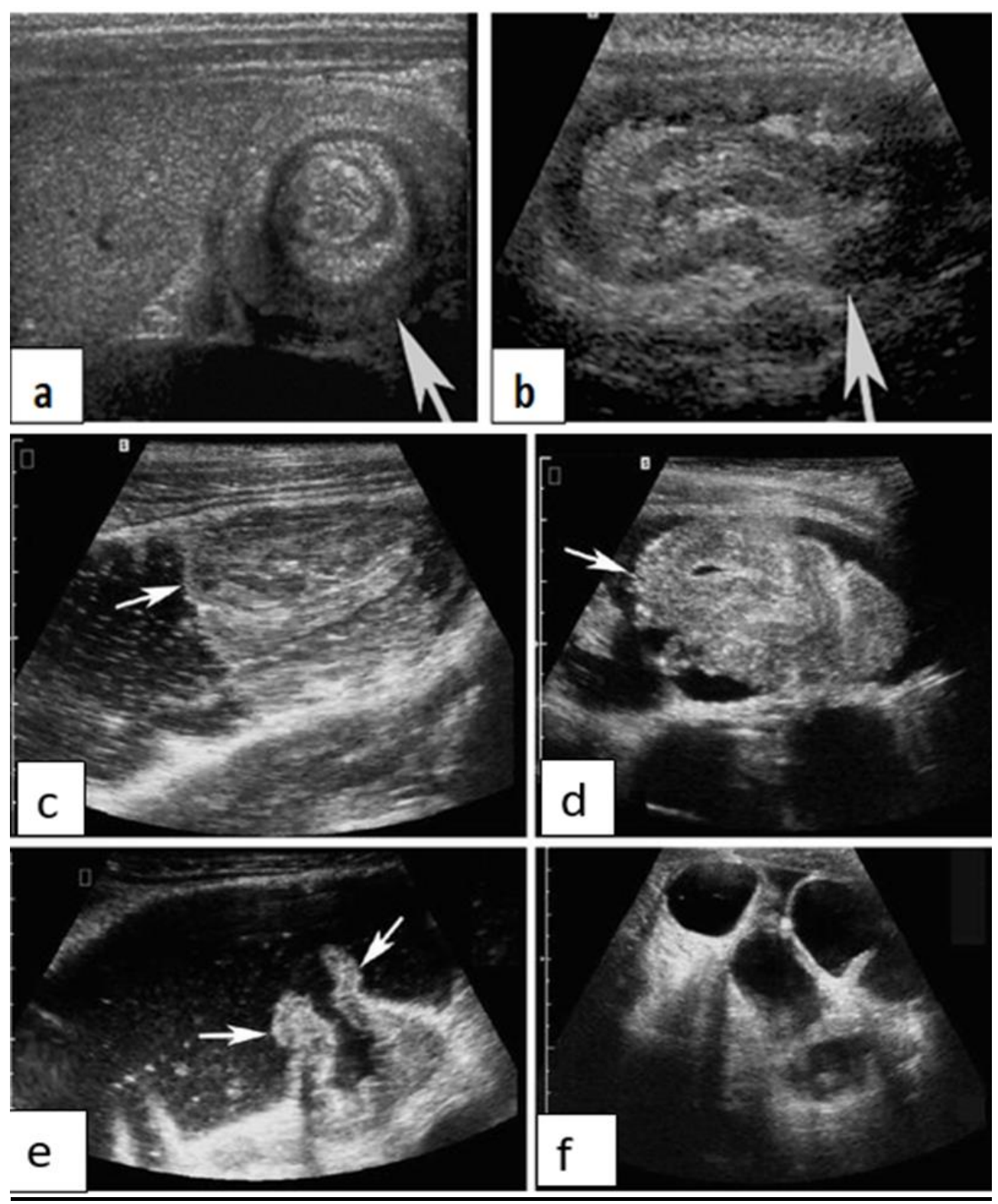

Figure 1: (a) transverse plane showing a heterogenous target like mass with multiple concentric rings (arrow). (b) a pseudokidney shaped mass (arrow). (c) The typical sandwich sign (arrow) is seen as the head of intussusception is forced backwards towards the ileocecal valve by fluid enema. (d) In the longitudinal plane, the head of intussusception (arrow) is surrounded by echofree fluid proximal to the ileocecal valve. (e) The ileocecal valve (arrows) is visible after effective reduction, with fluid flowing freely into the ileum. (f) The reduction enema fluid is visualized being poured into the ileal loops (honey comb appearance). 


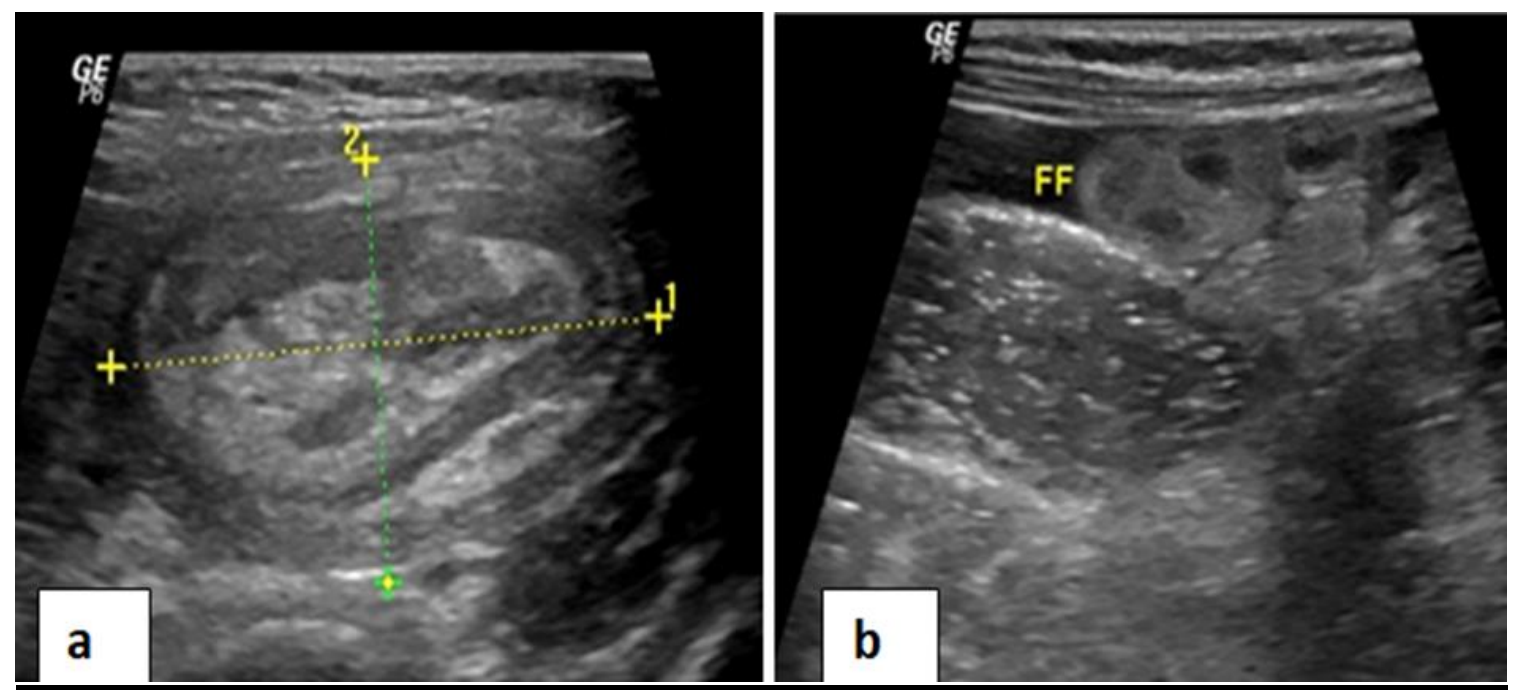

Figure 2: (a) Sandwich or pseudokidney sign. (b) Presence of free fluid and distended proximal bowel loop.

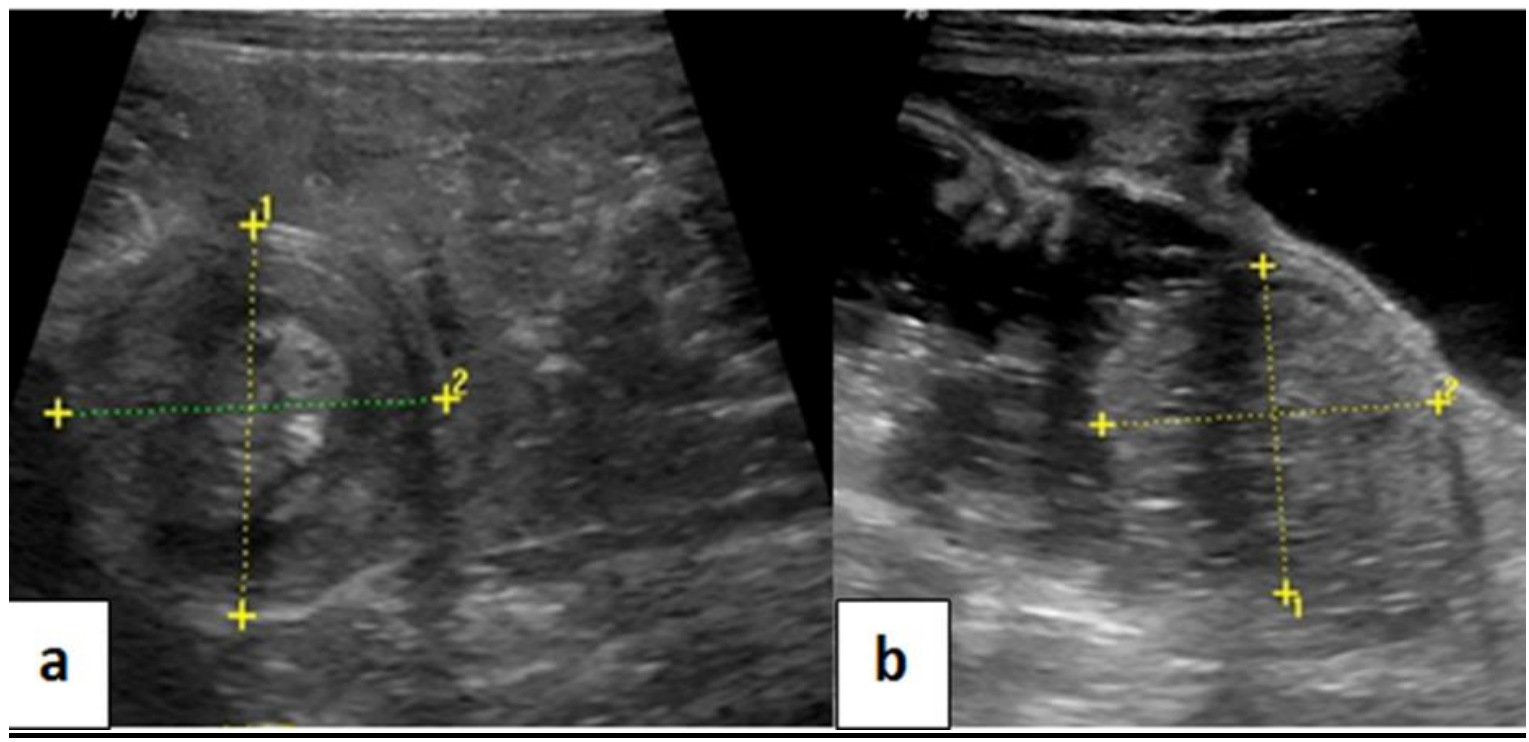

Figure 3: (a) a heterogenous mass with central multiple concentric rings (target sign) (b) US scan after hydrostatic reduction showed the presence of a residual mass. 


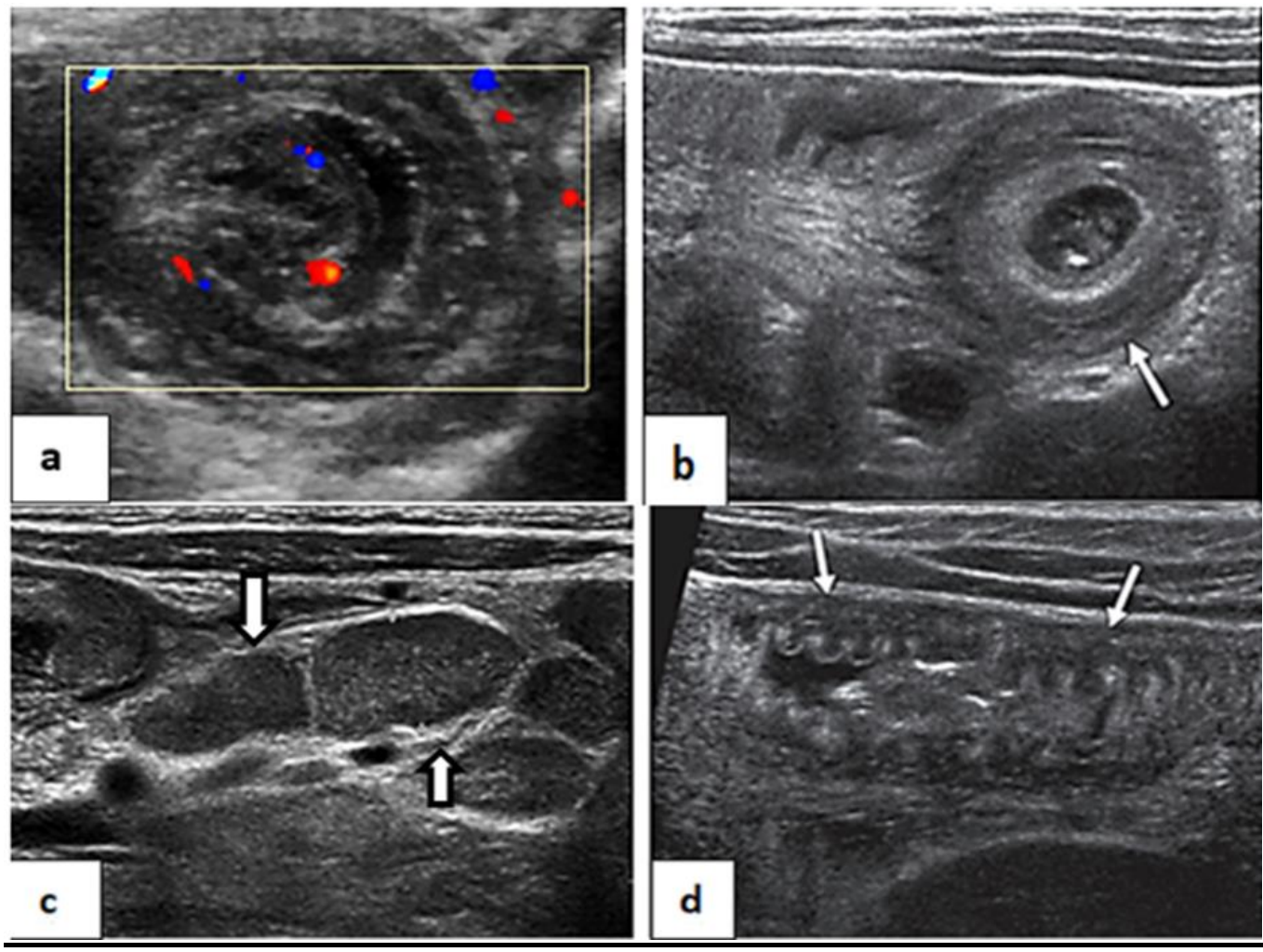

Figure 4: (a) initial ultrasound scanning showed the target sign of intussusception. (b) The mass with severe bowel wall thickening (arrow). (c) On the follow-up scan after reduction, a transverse image shows numerous enlarged mesenteric lymph nodes (arrows). (d) A sagittal image shows marked thickening of the bowel wall (arrows).

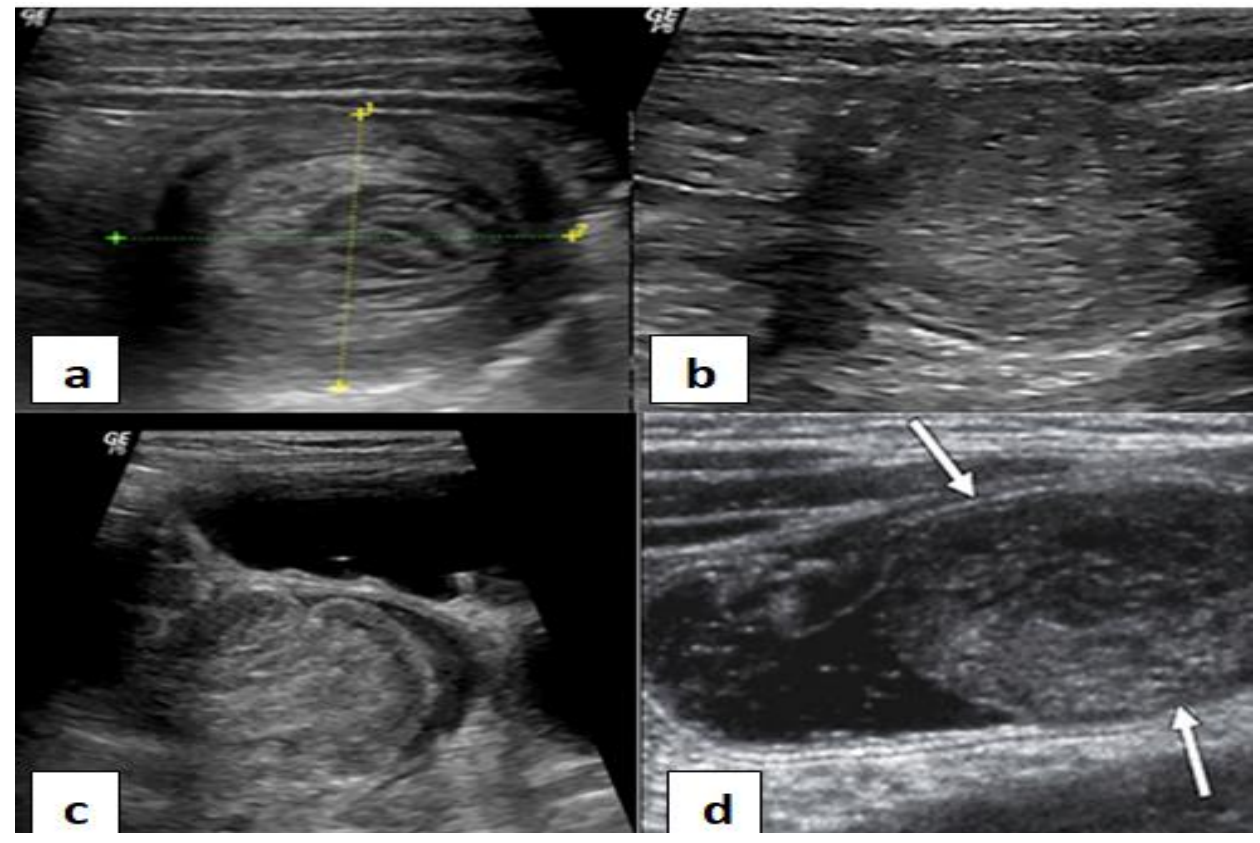

Figure 5: (a) The intussusception as a target sign in the short axis. (b) a typical sonographic appearance of a polyp containing small cysts with the evidence of its stalk. (c \& d) During saline infusion per rectum, ultrasound images show the polyp (arrows) surrounded by fluid, confirming its colonic intraluminal location. 

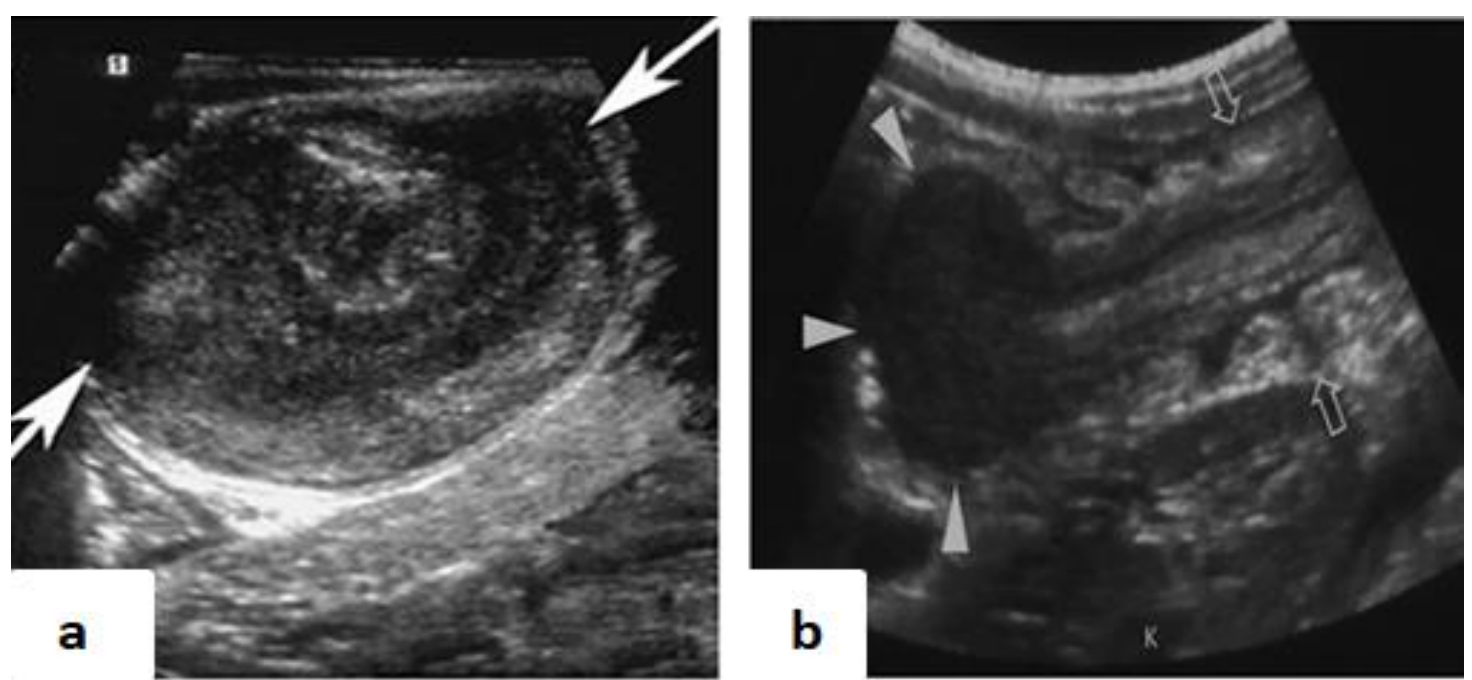

Figure 6: (a) a large heterogenous mass (arrows) with a central target like structure. (b) sagittal image showing telescoped two bowels (between open arrows) and a hypoechoic mass at the neck of the intussusception (arrowheads), K (kidney).

\section{RESULTS:}

The hydrostatic reduction was expected to assist paediatric patients with intussusception in this cross-sectional study. The patients that met the inclusion criteria were eight months old on average and ranged in age from four to 36 months. Males made up $51.4 \%$ of the population, while females made up $48.6 \%$. As a result, the male-to-female ratio is around 1:1.

The time it takes between the onsets of symptoms to the patient seeking medical help by patients' guardians ranged from 4 to 72 hours, with a median of 24 hours. Twenty-six patients presented within 24 hours, while 11 patients presented late after 24 hours. Regarding clinical presentation, 83.8\% had abdominal pain. Median abdominal pain duration was 24 hours and ranged from 12 to 72 hours. About twothirds of patients (64.9\%) had vomiting. The median vomiting duration was 24 hours and ranged from 12 to 72 hours. Red currant jelly was present in 59.5\%. Its median duration was 12 hours and ranged from two to 24 hours. Only $16.2 \%$ presented with diarrhea. Median diarrhea duration was 36 hours and ranged from 24 to 72 hours.

Intussusception Mass was present in all studied patients (100.0\%). Free fluid was found in $45.9 \%$ of the studied patients. Pathological lead points were present in $10.8 \%$ of the patients. The most frequent intussusception type was Ileo-colic (56.8\%), 
followed by Ileo-ileocolic $(27.0 \%)$. The least frequent type was Ileo-ileal (5.4\%).

More than two-thirds of patients underwent one trial of hydrostatic reduction (86.5\%). Only $10.8 \%$ and $2.7 \%$ underwent two and three trials, respectively.

Six patients (16.2\%) underwent surgery. Four of them had failed HR, while two cases had surgical intervention following successful HR as they had pathological lead points. Residual mass was present in $10.8 \%$ of patients. Nineteen percent had free fluid, and $18.9 \%$ suffered from recurrence (Figure 7).

Four cases had only one episode of recurrence (less than three episodes), while there were three cases that suffered from more than three episodes. The median age was significantly higher in those who experienced recurrence (18 months) than those who didn't experience recurrence ( 8 months). The P-value was 0.008. There was no significant difference regarding gender. The P-value was 1.

There was no significant difference in abdominal pain, vomiting, red currant jelly, diarrhoea, free fluid, or kind of intussusception between individuals with and without recurrence. Logistic regression was done for the prediction of recurrence. It revealed that age was a significant predictor for intussusception recurrence $(\mathrm{OR}=1.1124$ \& $95 \%$ C.I. ranged from 1.029 to 1.227$)$. The P-value was 0.01 (Table 1).

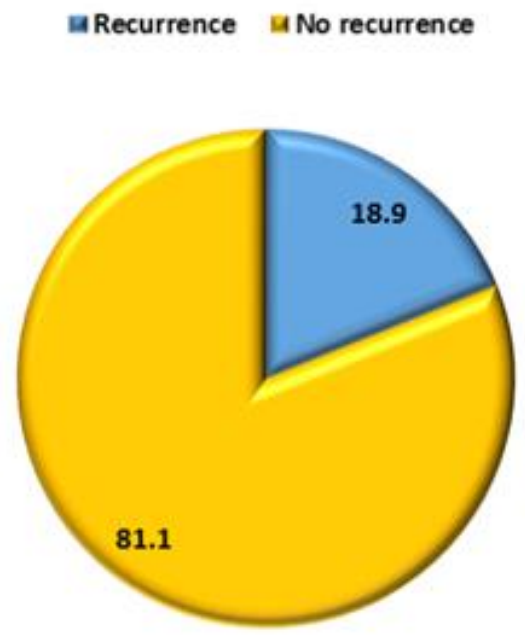

Figure 7: Intussusception recurrence rate in the studied patients 
Table 1: Logistic regression analysis for prediction of recurrence in intussusception patients

\begin{tabular}{|c|c|c|c|c|c|}
\hline & $\mathbf{B}$ & S.E. & Wald & OR $(95 \%$ CI $)$ & P value \\
\hline Age (months) & $0.1: 7$ & $0.0+5$ & 6.729 & $1.12+i 1.029-1.27 ?$ & 0.0 \\
\hline
\end{tabular}

\section{Discussion:}

During the duration of this cross-sectional study, 40 children with intussusceptions were managed. Three of them were ruled out because one had a bowel perforation that was later proved to be caused by gangrenous intestine during surgery, and another had a gangrenous loop without a perforation. The third case was reduced on its own.

Thirty-seven patients fulfilled the inclusion criteria and were enrolled. The patients in the study ranged in age from 4 to 36 months and had a median age of 8 months. $70.3 \%$ of them were $\leq 1$ year. It is fairly similar to a previous study (12). Also, we found that the male-to-female ratio was nearly one-to-one. That is not in line with other studies which mostly recorded the male dominance $(12 \&$ 13).

Symptoms ranged from around 4 to 72 hours, with a median of 24 hours. This result is consistent with other studies' findings, with colicky abdominal discomfort being the most common symptom (83.3\%) (4\&14).
However, vomiting has been described as the most prevalent symptom in certain studies (15 \& 16). It's possible that the variation in presenting symptoms is linked to the stage of the disease or the time of admission to the hospital. Intussusception induces abdominal discomfort, causing the infant to bring his knees towards his chest. Intussusception is thought to be caused by viral infections of the respiratory or gastrointestinal system, which lead to hyperplasia of lymphoid tissues such as Peyer's patches. The swollen Peyer's patches may then become a trigger of intussusception (17). In separate studies, they found a link between antecedent diarrheal or respiratory disease and an elevated risk of intussusception $(18,19)$. Our findings are consistent with theirs, as six of our patients complained of diarrhea and gastroenteritis prior to presenting with an intussusception mass. 
The most prevalent type of intussusception in this sample was ileocolic (idiopathic). This is in line with what most series have observed $(13,20 \& 21)$. Other forms of intussusceptions in children include ileoileal, colocolic, and ileoileo colic, although they are significantly less prevalent than the ileocolic type. Intussusception can occur anywhere in the bowel when a pathologic lead point (PLP) is present. Four cases with (PLP) were included in this study. One of them was known to be Henoch-Schönlein purpura (HSP); it presented with abdominal pain, purpuric rash and bilateral knee tender swelling. After effective hydrostatic reduction of the intussusception mass, the ultrasonography revealed intestinal thickness, numerous enlarged mesenteric lymph nodes, which were treated with prednisone for 3 weeks. The three others underwent further surgical intervention; one was secondary to Burkitt's lymphoma. The other two cases were due to polyps.

The ascending and transverse colons were the most frequent sites of intussusception (9). This is also what the present study concluded. The location of intussusception is determined by the length of the mesentery and the time of admission to the hospital. Also, prolapsing of intussusception through the anus can occur in late-presenting patients (22), as we found in one case.

Age, duration of symptoms, and rectal bleeding have all been studied as variables that may have a detrimental impact on the success of enema reduction $(23,24 \& 25)$. In our study, most cases had been successfully reduced by USGHR. Only four cases failed with HR. It is a very good outcome, but we can't analyze factors that have a negative influence on HR, so we recommend further studies with larger sample size allowing for exploring factors affecting the reduction rate in our hospital.

In the current study, the reduction was successful in $89.2 \%$ of patients (Figure 8). This was essentially identical to the findings of other researchers ( $26 \& 27)$, who reported a success rate of more than $84 \%$ for ultrasonic guided hydrostatic reduction, which was somewhat higher than other study's 75\% success rate (9). Also, a similar study reported a $100 \%$ success rate of saline hydrostatic reduction in a group of 14 kids (28).

After non-operative reduction of intussusceptions, the recurrence rate ranges from 5 to $20 \%$, with a mean of $10 \%$ (18). The recurrence rate was 18.7 percent in the current study. Recurrent intussusception, 
according to the literature, is treatable by USGHR, even if it occurs multiple times (18), we had successful reduction nonoperatively of all recurred cases. Only two cases of them needed further planned surgery, as they had pathological lead points. Parents' early recognition of recurrence due to their awareness plays a role in these situations.

Not more than 15 minutes, we used a sustained pressure of $100-120 \mathrm{~cm} \mathrm{H} 2 \mathrm{O}$ and waited until the intussusceptum diminished or the retrograde movement halted. Because of the evenly distributed pressure of the saline on the gut wall, our approach produced satisfactory results without any procedure-related complications. This is exactly what some other researchers discovered when they observed that saline exerts more equally distributed pressure on the gut wall than air (29).

Logistic regression was done for the prediction of recurrence. It revealed that age was a significant predictor for intussusception recurrence. The median age was significantly higher in those who experienced recurrence (18 months) than those who didn't experience recurrence $(8$ months), This is consistent with the findings of that study, which found that patients with intussusception who are older than one year of age are more likely to have their intussusception reoccur (30). However, there was no significant difference in gender, presenting symptoms, or type of intussusception between those who had recurrence and those who did not.

Patients who had a successful HR stayed under observation from 12 to 24 hours, whereas those who needed surgery stayed up to 3 days. In this series, there were no procedure-related sequelae. In addition, no one died.

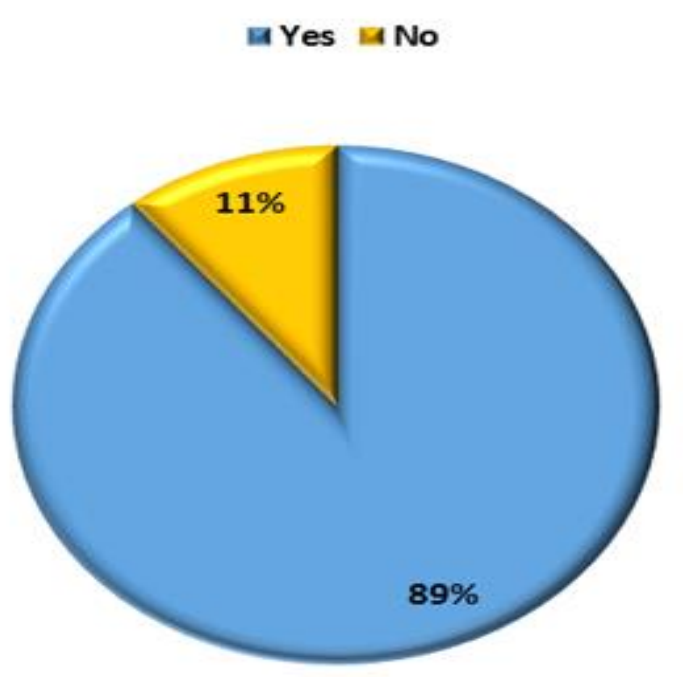

Figure 8: Intussusception reduction rate in the studied patients 


\section{Conclusion and recommendations:}

Ultrasound guided hydrostatic reduction is a safe, effective, and high-success procedure that does not require radiation exposure. So, we recommend:

- Adoption of this procedure as a primary treatment option in non-complicated intussusception cases in all health care centers for children .

- Further studies with large samples allowing for exploration factors affect the rate of hydrostatic reduction in our hospital.

- A general study to assess the availability and expertise of this procedure in Egypt.

\section{References:}

1. World Health Organization. Acute intussusception in infants and children: incidence, clinical representation and management: a global perspective. World Health Organization; 2002.

2. Shekherdimian, Shant, and Steven L. Lee. "Management of pediatric intussusception in general hospitals: diagnosis, treatment, and differences based on age." World Journal of Pediatrics 7, no. 1 (2011): 70-73.

3. Tang XB, Zhao JY, Bai YZ. Status survey on enema reduction of paediatric intussusception in China. Journal of International Medical Research. 2019 Feb;47(2):859-66.

4. Mandeville K, Chien M, Willyerd FA, Mandell G, Hostetler MA, Bulloch B. Intussusception: clinical presentations and imaging characteristics. Pediatric emergency care. 2012 Sep 1;28(9):842-4.

5. Digant, Shastri Mona, Seth Rucha, and Dessai Eke. "Ultrasound guided reduction of an ileocolic intussusception by a hydrostatic method by using normal saline enema in paediatric patients: a study of 30 cases." Journal of clinical and diagnostic research: JCDR 6, no. 10 (2012): 1722.

6. Marsicovetere P, Ivatury SJ, White B, Holubar SD. Intestinal intussusception: etiology, diagnosis, and treatment. Clinics in colon and rectal surgery. 2017 Feb;30(01):030-9.

7. Clark AD, Hasso-Agopsowicz M, Kraus MW, Stockdale LK, Sanderson CF, Parashar UD, et al. Update on the global epidemiology of intussusception: a systematic review of incidence rates, age distributions and case-fatality ratios among children aged< 5 years, before the introduction of rotavirus vaccination. International journal of epidemiology. 2019 Aug 1;48(4):131626.

8. Strouse, Peter J., and Anastasia L. Hryhorczuk. "Validation of US as a first-line diagnostic test for assessment of pediatric ileocolic intussusception: reply to letter from Cohen." Pediatric Radiology 40, no. 5 (2010): 789-790.

9. Mensah Y, Glover-Addy H, Etwire V, AppeaduMensah W, Twum M. Ultrasound guided hydrostatic reduction of intussusception in children at Korle $\mathrm{Bu}$ Teaching Hospital: an initial experience. Ghana medical journal. 2011 Sep;45(3):128.

10. Xiaolong, Xie, Wu Yang, Wang Qi, Zhao Yiyang, and Xiang Bo. "Risk factors for failure of hydrostatic reduction of intussusception in pediatric patients: A retrospective study." Medicine 98, no. 1 (2019).

11. He N, Zhang S, Ye X, Zhu X, Zhao Z, Sui X. Risk factors associated with failed sonographically guided saline hydrostatic intussusception reduction in children. Journal of Ultrasound in Medicine. 2014 Sep;33(9):1669-75.

12. Fakhry T, Fawzy AN, Mahdy AT. The efficacy of delayed, repeated reduction enema in management of intussusception. Annals of Pediatric Surgery. 2021 Dec;17(1):1-5.

13. Chukwubuike KE, Nduagubam OC. Hydrostatic reduction of intussusception in children: a single 
centre experience. The Pan African Medical Journal. 2020;36.

14. Talabi AO, Famurewa OC, Bamigbola KT, Sowande OA, Afolabi BI, Adejuyigbe O. Sonographic guided hydrostatic saline enema reduction of childhood intussusception: a prospective study. BMC emergency medicine. 2018 Dec;18(1):1-7.

15. Khorana J, Singhavejsakul J, Ukarapol N, Laohapensang M, Wakhanrittee J, Patumanond J. Enema reduction of intussusception: the success rate of hydrostatic and pneumatic reduction. Therapeutics and clinical risk management. 2015;11:1837.

16. Talabi AO, Sowande OA, Etonyeaku CA, Adejuyigbe O. Childhood intussusception in Ileife: What has changed? African Journal of Paediatric Surgery. 2013 Jul 1;10(3):239.

17. Lee YW, Yang SI, Kim JM, Kim JY. Clinical features and role of viral isolates from stool samples of intussuception in children. Pediatric gastroenterology, hepatology \& nutrition. 2013 Sep;16(3):162.

18. Okimoto S, Hyodo S, Yamamoto M, Nakamura K, Kobayashi M. Association of viral isolates from stool samples with intussusception in children. International Journal of Infectious Diseases. 2011 Sep 1;15(9):e641-5.

19. Mansour AM, El Koutby M, El Barbary MM, Mohamed W, Shehata S, El Mohammady H, et al. Enteric viral infections as potential risk factors for intussusception. The Journal of Infection in Developing Countries. 2013 Jan 15;7(01):028-35.

20. Chalya PL, Kayange NM, Chandika AB. Childhood intussusceptions at a tertiary care hospital in northwestern Tanzania: a diagnostic and therapeutic challenge in resource-limited setting. Italian journal of pediatrics. 2014 Dec;40(1):1-8.

21. Williams H. Imaging and intussusception. Archives of Disease in Childhood-Education and Practice. $2008 \mathrm{Feb} 1 ; 93(1): 30-6$.
22. Ibrahim-Ibrahim A. Prolapsed ileocolic intussuception. Ann Pediatr Surg. 2011;7:76-8.

23. Nayak D, Jagdish S. Ultrasound guided hydrostatic reduction of intussusception in children by saline enema: our experience. Indian Journal of Surgery. 2008 Feb;70(1):8-13.

24. Fallon SC, Lopez ME, Zhang W, Brandt ML, Wesson DE, Lee TC, et al. Risk factors for surgery in pediatric intussusception in the era of pneumatic reduction. Journal of pediatric surgery. 2013 May 1;48(5):1032-6.

25. Ramachandran $P$, Gupta A, Vincent $P$, Sridharan $S$. Air enema for intussusception: is predicting the outcome important? Pediatric surgery international. 2008 Mar;24(3):311-3.

26. Ahmad MM, Wani MD, Dar HM, Mir IN, Wani HA, Raja AN. An experience of ultrasound-guided hydrostatic reduction of intussusception at a tertiary care centre. South African Journal of Surgery. 2016 May 6;54(1):10-3.

27. Gfroerer S, Fiegel H, Rolle U. Ultrasound-guided reduction of intussusception: a safe and effective method performed by pediatric surgeons. Pediatric surgery international. $2016 \mathrm{Jul} ; 32(7): 679-82$.

28. Sanchez TR, Doskocil B, Stein-Wexler R. Nonsurgical management of childhood intussusception: retrospective comparison between sonographic and fluoroscopic guidance. Journal of Ultrasound in Medicine. 2015 Jan;34(1):59-63.

29. Karadağ ÇA, Abbasoğlu L, Sever N, Kalyoncu MK, Yıldız A, Akın M, et al. Ultrasound-guided hydrostatic reduction of intussusception with saline: safe and effective. Journal of pediatric surgery. 2015 Sep 1;50(9):1563-5.

30. Ye X, Tang R, Chen S, Lin Z, Zhu J. Risk factors for recurrent intussusception in children: a systematic review and meta-analysis. Frontiers in pediatrics. 2019 Apr 16;7:145.

To cite this article: Medhat M. Refaat, Shorouk Z. Abdel Aziz, Hadeel B. Abdelmageed. Ultrasound guided hydrostatic reduction of intussusception using saline enema in pediatric population, does it worth? BMFJ 2022; 39 (radiology):171-186. DOI: 10.21608/bmfj.2021.77129.1422 